\title{
Elective operations for left ventricular asynergy
}

\author{
FRANK GERBODE, WILLIAM J. KERTH, \\ J. D O N A D H ILL, SACHINANDAN BANER JEE ${ }^{1}$, \\ and CARLO MAR CELLETTI ${ }^{1}$
}

Department of Cardiovascular Surgery, Presbyterian Hospital, and Heart Research Institute of the Institutes of Medical Science, Pacific Medical Center, San Francisco, California 94115, USA

Gerbode, F., Kerth, W. J., Hill, J. D., Banerjee, S., and Marcelletti, C. (1974). Thorax, 29, 282-286. Elective operations for left ventricular asynergy. Operative results in 45 patients with symptomatic left ventricular asynergy are reviewed. The main symptoms were congestive heart failure in $77.7 \%$, angina in $31.1 \%$, arrhythmias in $11.1 \%$, and systemic thromboembolism in $2 \cdot 2 \%$ of the patients.

All patients had left heart catheterization, 40 had left ventricular angiography, and 27 had selective coronary arteriography. The last myocardial infarction occurred within three months preoperatively in 15 patients and more than 13 months prior to surgery in 27 patients.

The cardiac index was $1.51 / \mathrm{m}^{2} / \mathrm{min}$ or less in six patients and the left ventricular end diastolic (LVED) pressure was $25 \mathrm{mmHg}$ or higher in 15 patients.

All patients were operated upon electively with the use of cardiopulmonary bypass. Excision of the left ventricular aneurysm was performed in 39 cases and plication in six.

The immediate survival rate was $66.6 \%$. The lowest mortality rate was among patients with angina (12.5\%) and the highest in those with association of congestive heart failure and angina $(66 \cdot 6 \%)$.

The mortality rates among patients with recent or old myocardial infarction were 46.6 and $22.2 \%$ respectively.

One of the six patients with a cardiac index of $1.51 / \mathrm{m}^{2} / \mathrm{min}$ or less and seven of the 15 patients with LVED pressure of $25 \mathrm{mmHg}$ or higher were discharged from hospital.

It is concluded that ventricular aneurysmectomy has to be considered an elective procedure in order to obtain predictable results and that ideal indications for operation are angina or congestive heart failure refractory to medical treatment, associated with acceptable haemodynamics, a cardiac index of $2.01 / \mathrm{m}^{2} / \mathrm{min}$ or higher, and a LVED pressure below $25 \mathrm{mmHg}$.

Beck (1944) was the first to describe a planned operation for a ventricular aneurysm by external reinforcement with pericardium and fascia lata. Likoff and Bailey (1955) reported the use of clamps for a left ventricular aneurysmectomy by a closed heart technique, and Cooley, Collins, Morris, and Chapman (1958) reported the first open excision using cardiopulmonary bypass. Since then, a number of reports have been published on left ventricular aneurysmectomy with the use of cardiopulmonary bypass (Cooley and Hallman, 1968; Favaloro et al., 1968; Key, Aldridge, and

${ }^{1}$ Former Fellow in Cardiovascular Surgery, Department of Surgery, Stanford University School of Medicine, at Pacific Medical Center, San Francisco, California, 94115
MacGregor, 1968; Lindesmith et al., 1970; Kay et al., 1970; Schattenberg, Giuliani, Campion, and Danielson, 1970; Tice, Cheng, and Dolgin, 1970; Kluge et al., 1971; Loop, 1971; Graber et al., 1972; Stoney, Alford, Burrus, and Thomas, 1973).

Between 1960 and December 1972 at the Pacific Medical Center in San Francisco, a total of 75 left ventricular aneurysmectomies were performed in patients with cineangiographic evidence of abnormal motion of the left ventricle, according to Gorlin's functional definition (Gorlin, Klein, and Sullivan, 1967), associated with clinical cardiac symptoms either chronic or acute. The overall operative results have been reported elsewhere (Gerbode et al., 1974). 
This report analyses the indications for surgical treatment and the results in a group of 45 patients who were electively operated upon and had preoperative haemodynamic evaluation by means of left heart catheterization.

\section{MATERIAL AND METHOD}

Of the 45 patients, 38 were male and seven female, a ratio of $5.4: 1$. Their ages ranged between 30 and 74 (mean 58) years.

The main symptoms were those of congestive heart failure in $35(77 \cdot 7 \%)$ patients, angina in $14(31.1 \%)$, arrhythmias in five $(11 \cdot 1 \%)$, and systemic thromboembolism in one $(2 \cdot 2 \%)$.

The indications for operation included intractable congestive heart failure in 26 patients, angina in eight, life-threatening arrhythmias in two, association of congestive heart failure with angina in six, and congestive heart failure with arrhythmias in three patients.

Apart from the routine examination, all 45 patients had left heart catheterization, 40 had left ventricular angiography, 26 had selective coronary angiography, and 27 had complete haemodynamic and angiocardiographic studies.

Of a total of 42 patients with documented electrocardiographic evidence of either single or multiple myocardial infarctions, 15 had their last myocardial infarction within three months of operation and 27 more than three months prior to operation.

According to the selective coronary angiographic studies, 14 patients had three vessel disease, 10 had two vessel disease and two patients had single vessel disease.

All patients were operated upon using cardiopulmonary bypass with normothermia or moderate hypothermia and intermittent aortic cross-clamping. Excision of left ventricular aneurysm was performed in 39 patients and a plication technique was used in six cases. Mural thrombosis was found in 13 patients.

The aneurysmectomy was combined with mitral and/or aortic commissurotomy and/or valve replacement in four cases, closure of postmyocardial infarction ventricular septal defect in one, and single or multiple aorta to coronary artery saphenous vein bypass grafts in 16 patients.

\section{RESULTS}

Thirty patients were discharged from hospital, an immediate survival rate of $66.6 \%$.

A correlation between the main symptoms and the hospital deaths is shown in Table $I$. The angina group appeared to have the lowest hospital death rate $(12.5 \%)$. The three patients with symptoms of congestive heart failure associated with arrhythmias were all discharged from hospital after operation.
T A B L E I

MAIN PREOPERATIVE SYMPTOMS IN 45 PATIENTS WITH LEFT VENTRICULAR ASYNERGY TREATED SURGICALLY

\begin{tabular}{l|c|cc}
\hline \multicolumn{1}{c|}{ Main Symptoms } & No. of Patients & & \multicolumn{2}{c}{ Hospital Deaths } \\
CHF & 26 & 9 & $\%$ \\
Angina & 8 & 1 & 34.6 \\
Arrhythmias & 2 & 1 & 12.5 \\
CHF and angina & 6 & 4 & 66.6 \\
CHF and arrhythmias & 3 & 0 & 0.0 \\
\hline
\end{tabular}

$\overline{\mathrm{CHF}}=$ congestive heart failure.

Table II refers to the time of the procedure in relation to the last documented myocardial infarction and relative hospital mortality rates. The hospital deaths were seven $(46.6 \%)$ among the 15 patients who had their last myocardial infarction less than three months before operation and six $(22.2 \%)$ among the 27 patients in whom the operation was performed later than three months after the last documented myocardial infarction.

\section{T A B L E I I}

TIME OF OCCURRENCE OF LAST MYOCARDIAL INFARCTION PRIOR TO SURGICAL TREATMENT IN 45 PATIENTS

\begin{tabular}{l|c|cc}
\hline $\begin{array}{c}\text { Last Myocardial } \\
\text { Infarction prior } \\
\text { to Surgery }\end{array}$ & No. of Patients & \multicolumn{2}{|c}{ Hospital Deaths } \\
\cline { 2 - 4 } & 15 & 7 & $\%$ \\
\hline $\begin{array}{l}\text { Less than three months } \\
\text { More than three months }\end{array}$ & 27 & 6 & $22 \cdot 2$ \\
\hline
\end{tabular}

Table III shows the preoperative haemodynamic status of the patients grouped according to their main symptoms.

\section{T A B L E I I I}

PREOPERATIVE HAEMODYNAMIC DATA IN 45 PATIENTS WITH LEFT VENTRICULAR ASYNERGY

\begin{tabular}{l|c|c|c}
\hline \multicolumn{1}{c|}{ Main Symptoms } & $\begin{array}{c}\text { No. of } \\
\text { Patients }\end{array}$ & $\begin{array}{c}\text { Mean CI } \\
\left(\mathrm{C} / \mathrm{m}^{2} /\right. \\
\mathrm{min})\end{array}$ & $\begin{array}{c}\text { Mean LVEDP } \\
\text { (mmHg) }\end{array}$ \\
\cline { 1 - 3 } CHF & 26 & $2 \cdot 05$ & 25 \\
Angina & 8 & $2 \cdot 6$ & $14 \cdot 2$ \\
Arrhythmia & 2 & 1.85 & 23.5 \\
CHF and angina & 6 & 2.03 & 14.8 \\
CHF and arrhythmia & 3 & $2 \cdot 73$ & 17 \\
\hline
\end{tabular}

CHF = congestive heart failure.

CI = cardiac index (at rest).

LVEDP = left ventricular end diastolic pressure (at rest).

\section{DISCUSSION}

Experimental and clinical attempts to outline the pathophysiological implications of left ventricular asynergy and to quantitate its haemodynamic effects are being carried out with the aid of the most recent cardiodiagnostic techniques.

Measurements of ventricular performance in the presence of postinfarction myocardial asyn- 
ergy have shown that when an area of akinesis approaches $20-25 \%$ of the left ventricular surface area, the extent of fibre shortening required of the functioning myocardium begins to exceed physiological limits (Austen et al., 1962; Herman, Heinle, Klein, and Gorlin, 1967; Klein, Herman, and Gorlin, 1967; Herman and Gorlin, 1969).

The coronary circulation, handicapped by atherosclerosis, may not be able to deliver the additional oxygen required (Ellis, 1971). The clinical verification of the above observation is the fact that congestive heart failure and angina are the most common symptoms of left ventricular asynergy (Davis and Ebert, 1972). In our series these symptoms were present in $77.7 \%$ and $31 \cdot 1 \%$ respectively.

Experimental studies have recently claimed that removal of over $30-35 \%$ of the canine left ventricular myocardium does not permit survival (Stein and Cordell, 1969). Therefore, the surgical treatment of symptomatic left ventricle asynergy in patients where the area of resectable muscle is within a narrow range is a complicated matter.

As stated in the introduction, we have accepted the functional definition of left ventricular aneurysm, and the consequent selection of candidates for operation makes our report not comparable with those of other authors (Cooley et al., 1958; Favaloro et al., 1968; Kay et al., 1970; Schattenberg et al., 1970; Loop, 1971; Graber et al., 1972; Stoney et al., 1973) who have used Edwards' (1961) definition of left ventricular aneurysm as 'a protrusion of a localized portion of the external aspect of the left ventricle beyond the remainder of the cardiac surface with simultaneous protrusion of the cavity as well'. This definition selects a population of patients with a clear anatomical lesion and may account for better surgical results.

Our hospital mortality rates are closer to those reported by Kay et al. $(1970-32 \%)$ and by Lindesmith et al. (1970-26\%). Both these authors have selected their patients on the basis of symptomatic left ventricular asynergic areas. Our hospital mortality of $30 \%$ decreased to $22.2 \%$ in patients who had the operation more than three months after their last myocardial infarction, as suggested by Lindesmith et al. (1970).

A certain time interval is needed for the necrotic wall of the left ventricle to be converted into fibrous tissue in order to hold sutures securely. But even more important is the fact that the operation should be deferred until time has allowed the left ventricle to adapt itself to the new haemodynamic situation of an asynergic area and the increased mechanical load required by the remaining functional myocardium.

Other significant considerations arise when the preoperative haemodynamic status is taken into account.

The cardiac index was found to be $1.51 / \mathrm{m}^{2} / \mathrm{min}$ or less in six of our patients and only one of them was discharged from hospital. A LVED pressure of $25 \mathrm{mmHg}$ or higher was found in a group of 15 patients of whom only seven left hospital.

The best surgical results were obtained in patients whose main symptoms were angina or congestive heart failure associated with arrhythmias. These two groups of patients were characterized by the best preoperative haemodynamic status with a mean cardiac index above 2.0 $1 / \mathrm{m}^{2} / \mathrm{min}$ and a mean LVED pressure below $25 \mathrm{mmHg}$. In the congestive heart failure group, the difference of mean cardiac index and LVED pressure between survivors and deaths was 2.2 versus $1.71 / \mathrm{m}^{2} / \mathrm{min}$ and 23.4 versus $28.5 \mathrm{mmHg}$.

We feel that only a very accurate preoperative or intraoperative quantification of the amount of resectable left ventricle could give absolute indication or contraindication for aneurysmectomy. This stage of accuracy has not yet been reached in the treatment of postinfarction left ventricular asynergy.

A critical clinical evaluation of symptoms associated with measurements of cardiac index and LVED pressure can still provide useful criteria for surgical treatment.

\section{CONCLUSION}

From the review of our experience in the surgical management of symptomatic left ventricular asynergy the following conclusions could be drawn:

(a) Wide clinical differences in the population of candidates for left ventricular aneurysmectomy and the use of the anatomical or functional definition of left ventricular aneurysms are probably responsible for the conflicting results reported by various authors (Table IV).

(b) The operation of ventricular aneurysmectomy has to be considered essentially an elective procedure in order to obtain predictable results.

(c) Ideal indications for operation are angina and congestive heart failure refractory to medical treatment, associated with acceptable haemodynamics, that is, a cardiac index of $2.01 / \mathrm{m}^{2} / \mathrm{min}$ or more and a LVED pressure below $25 \mathrm{mmHg}$. 
T A B L E I V

PUBLISHED DATA ON LEFT VENTRICULAR ANEURYSMECTOMY ACCORDING TO DEFINITION OF THE LESION

\begin{tabular}{|c|c|c|c|}
\hline \multirow[b]{2}{*}{ Reference } & \multirow[b]{2}{*}{ No. of Patients } & \multicolumn{2}{|c|}{ Hospital Deaths } \\
\hline & & No. & $\%$ \\
\hline $\begin{array}{l}\text { Anatomical definition } \\
\text { Favaloro et al. (1968) } \\
\text { Cooley et al. (1968) } \\
\text { Graber et al. (1972) } \\
\text { Stoney et al. (1973) }\end{array}$ & $\begin{array}{r}130 \\
80 \\
23 \\
29\end{array}$ & $\begin{array}{r}17 \\
16 \\
5 \\
3\end{array}$ & $\begin{array}{l}13 \\
20 \\
21 \cdot 7 \\
10 \cdot 3\end{array}$ \\
\hline Total & 262 & 41 & $15 \cdot 6$ \\
\hline $\begin{array}{l}\text { Functional definition } \\
\text { Lindesmith et al. (1970) } \\
\text { Kay et al. (1970) } \\
\text { Tice et al.(1970) } \\
\text { PMC (1973) }\end{array}$ & $\begin{array}{l}38 \\
31 \\
14 \\
45\end{array}$ & $\begin{array}{r}10 \\
10 \\
0 \\
15\end{array}$ & $\begin{array}{r}26 \\
32 \\
0 \\
33\end{array}$ \\
\hline Total & 128 & 35 & $27 \cdot 3$ \\
\hline
\end{tabular}

PMC = Pacific Medical Center present series.

(e) The haemodynamic parameters are most valuable in screening the candidates for operation, and figures of cardiac index of $1.51 / \mathrm{m}^{2} / \mathrm{min}$ or less and LVED pressure of over $25 \mathrm{mmHg}$ contraindicate excision of areas of left ventricular asynergy.

Despite several uncertainties, mainly concerning a method for accurate anatomical definition of the site and amount of asynergic areas, operations for asynergy of the left ventricle have an important role in the management of a well selected group of patients in whom symptoms are not relieved by medical treatment.

As with most of the surgical approaches to acquired heart disease, ventricular aneurysmectomy is essentially a palliation complementary to medical therapy.

\section{REFERENCES}

Austen, W. G., Tsunekawa, T., Bender, H. W., Ebert, P. A., and Morrow, A. G. (1962). The acute hemodynamic effects of left ventricular aneurysm. An experimental study in dogs. Journal of Surgical Research, 2, 161.

Beck, C. S. (1944). Operation for aneurysm of the heart. A nnals of Surgery, 120, 34.

Cooley, D. A., Collins, H. A., Morris, G. C., and Chapman, D. W. (1958). Ventricular aneurysm after myocardial infarction. Journal of the American Medical Association, 167, 557.

and Hallman, G. L. (1968). Surgical treatment of left ventricular aneurysm: experience with excision of post-infarction lesions in 80 patients. Progress in Cardiovascular Disease, 11, 222.

Davis, R. W. and Ebert, P. A. (1972). Ventricular aneurysm, a clinical-pathologic correlation. American Journal of Cardiology, 29, 1.

Edwards, J. E. (1961). An Atlas of Acquired Diseases of the Heart and Great Vessels, Vol. II, p. 615. Saunders, Philadelphia.
Ellis, F. H., Jr. (1971). Surgery for chronic asynergy of the left ventricle: a current appraisal. Surgery, 70, 801.

Favaloro, R. G., Effler, D. B., Groves, L. K., Westcott, R. N., Suarez, E., and Lozada, J. (1968). Ventricular aneurysm-clinical experience. Annals of Thoracic Surgery, 6, 227.

Gerbode, F., Banerjee, S., Marcelletti, C., Hill, J. D., and Kerth, W. J. (1974). Surgical treatment of left ventricular aneurysm. Address: Rudolph Matas Memorial Lecture. Société Internationale de Chirurgie, Barcelona, September 1973. To be published.

Gorlin, R., Klein, M. D., and Sullivan, J. M. (1967). Prospective correlative study of ventricular aneurysm. American Journal of Medicine, 42, 512.

Graber, J. D., Oakley, C. M., Pickering, B. N., Goodwin, J. F., Raphael, M. J., and Steiner, R. E. (1972). Ventricular aneurysm; an appraisal of diagnosis and surgical treatment. British Heart Journal, 34, 830.

Herman, M. V. and Gorlin, R. (1969). Implications of left ventricular asynergy. American Journal of Cardiology, 23, 538.

-, Heinle, R. A., Klein, M. D., and Gorlin, R. (1967). Localized disorders in myocardial contraction. Asynergy and its role in congestive heart failure. New England Journal of Medicine, 227, 222.

Kay, H. J., Dunne, E., Krohn, B. G., Tsuji, H. K. Redington, J. V., Mendez, A., Dykstra, P., and Magidson, O. (1970). Left ventricular excision, exclusion, or plication for akinetic areas of the heart. Journal of Thoracic and Cardiovascular Surgery, 59, 139.

Key, J. A., Aldridge, H. E., and MacGregor, D. C. (1968). The selection of patients for resection of left ventricular aneurysm. Journal of Thoracic and Cardiovascular Surgery, 56, 477.

Klein, M. D., Herman, M. V., and Gorlin, R. (1967). A hemodynamic study of left ventricular aneurysm. Circulation, 35, 614.

Kluge, T. H., Ullal, S. R., Hill, J. D., Kerth, W. J., and Gerbode, F. (1971). Dyskinesia and aneurysm of the left ventricle; surgical experience in 36 patients. Journal of Cardiovascular Surgery, 12, 273.

Likoff, W. and Bailey, C. P. (1955). Ventriculoplasty: excision of myocardial aneurysm. Journal of the American Medical Association, 158, 915.

Lindesmith, G. C., Ellis, E. J., Stiles, Q. R., Meyer, B. W., and Jones, J. C. (1970). Surgical resection of non-functioning ventricular segments. American Journal of Surgery, 120, 226.

Loop, F. D. (1971). Ventricular aneurysmectomy. Surgical Clinics of North America. 51, 1071.

Schattenberg, T. T., Giuliani, E. R., Campion, B. C., and Danielson, G. K., Jr. (1970). Postinfarction ventricular aneurysm. Mayo Clinic Proceedings, 45, 13. 
Stein, M. and Cordell, A. R. (1969). Arrhythmias and left ventricular efficiency following infarction and infarctectomy. Archives of Surgery, 99, 802.

Stoney, W. S., Alford, W. C., Burrus, G. R., and Thomas, C. S., Jr. (1973). Repair of anteroseptal ventricular aneurysm. Annals of Thoracic Surgery, 15, 394.

Tice, D. A., Cheng, T. O., and Dolgin, M. (1970).
Surgical treatment of post-myocardial infarction scars (ventricular aneurysms). American Heart Journal, 80, 282.

Requests for reprints to: Dr. F. Gerbode, The Heart Research Institute of the Institutes of Medical Science, Pacific Medical Center, San Francisco, California, 94115. U.S.A. 